\title{
Pembinaan Nilai-Nilai Multikultural pada Masyarakat dalam Mengantisipasi Dampak Keberadaan Bandara Internasional Jawa Barat di Kecamatan Kertajati Kabupaten Majalengka
}

\author{
Yoyo Zakaria Ansori ${ }^{1}$, Indra Adi Budiman², Dede Salim Nahdi ${ }^{2}$ \\ 1,2 Universitas Majalengka
}

\begin{tabular}{|c|c|}
\hline Article History & ABSTRACT \\
\hline $\begin{array}{l}\text { Received } 07.07 .2019 \\
\text { Received in revised form } \\
22.09 .2019 \\
\text { Accepted } 05.10 .2019 \\
\text { Available online } 28.10 .2019\end{array}$ & $\begin{array}{l}\text { FOSTERING MULTICULTURAL VALUES IN THE COMMUNITY IN } \\
\text { ANTICIPATING THE IMPACT OF THE EXISTENCE OF THE WEST JAVA } \\
\text { INTERNATIONAL AIRPORT IN KERTAJATI DISTRICT, MAJALENGKA } \\
\text { REGENCY. The phenomenon of diversity is like a double-edged knife, one side } \\
\text { has a positive impact, that is, we have a rich diversity of cultural treasures, but the } \\
\text { other side also has a negative impact, because diversity can trigger conflicts } \\
\text { between community groups which in turn can cause instability in various fields. } \\
\text { This is what was tried to be facilitated through fostering multicultural values in } \\
\text { the community as an anticipatory effort towards the impact of the existence of the } \\
\text { West Java international airport in the Kertajati sub-district of Majalengka Regency } \\
\text { carried out by the Community Partnership Program (PKM) team. The purpose of } \\
\text { coaching activities is to increase the knowledge of multicultural values and have } \\
\text { the attitude of accepting other groups equally as a unit, regardless of cultural, } \\
\text { ethnic, gender, language, or religious differences. The method used in this } \\
\text { training includes the provision of material, discussion, question and answer, and } \\
\text { the application of the value internalization model, namely the value analysis } \\
\text { model. }\end{array}$ \\
\hline
\end{tabular}

DOI: $10.30653 / 002.201943 .167$

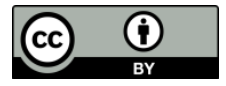

This is an open access article distributed under the terms of the Creative Commons Attribution 4.0 International License, which permits unrestricted use, distribution, and reproduction in any medium, provided the original work is properly cited. (c) 2019 Yoyo Zakaria Ansori, Indra Adi Budiman, Dede Salim Nahdi.

\section{PENDAHULUAN}

Bangsa dan masyarakat Indonesia sungguh berbangga memiliki kebudayaan yang beragam atau multikultural yang dapat dijadikan sebagai dasar pelaksanaan pembangunan berkelanjutan. Kekayaan budaya yang dimiliki bangsa Indonesia mesti

\footnotetext{
${ }^{1}$ Corresponding author: Program Studi PGSD, FKIP Universitas Majalengka; Jl. KH. Abdul Halim No. 23 Majalengka Jawa Barat; Email:
} ds.nahdi@gmail.com 
dipelihara dan dikembangkan sebagai dasar bagi pembangunan berkelanjutan. Di dalam penelitian etnologis misalnya, diketahui bahwa Indonesia terdiri atas kurang lebih 600 suku bangsa dengan identitasnya masing-masing serta kebudayaannya yang berbedabeda. Selain dari kehidupan suku-suku tersebut yang terkonsentrasi pada daerah-daerah tertentu, terjadi pula konsentrasi suku-suku di tempat lain karena migrasi atau karena mobilisasi penduduk yang cepat. Melalui sensus tercatat 200 lebih suku bangsa di Indonesia dengan jumlah total penduduk 237 juta jiwa sebagai warga Negara (Alwasilah, 2012, p. 111).

Kenyataan tersebut menempatkan Indonesia di urutan keempat negara yang populasinya tertinggi. Oleh karenanya pendidikan multikultural menemukan wadah dan relevansinya untuk konteks Indonesia yang memiliki semboyan "Bhinneka Tunggal Ika" yang artinya berbeda-beda tetapi satu tujuan. Kondisi itu diyakini sesuai dengan Indonesia pada saat ini, yang terdiri dari beragam suku, ras, budaya, bahasa, dan agama yang berbeda-beda tetapi dibingkai dalam kesatuan Indonesia. Menghadapi perbedaan tersebut, disatu sisi memberikan dampak positif yaitu sebagai sarana untuk saling mengenal dan mengisi kekurangan, namun pada sisi lain kondisi tersebut memberikan peluang terjadinya konflik (Tilaar, 2004). Sehingga kalau dibiarkan akan merusak keutuhan Negara Kesatuan Republik Indonesia.

Kondisi tersebut dimungkinkan akan terjadi pada masyarakat Desa Bantarjati Kecamatan Kertajati kalau tidak segera untuk mengantisipasinya. Keberadaan Bandara Internasional Jawa Barat akan menjadi magnet untuk datangnya masyarakat baru dari luar daerah yang berbeda suku, agama, ras, dan antar golongan sehingga potensi konflik sangat besar. Apalagi ditemukan fakta bahwa jalur utama kawasan sekitar bandara telah dimiliki oleh para pemilik modal dari etnis yang berbeda sehingga peluang benturan sangat besar. Menurut Huntington (1992) identitas budaya dan agama seseorang akan menjadi sumber konflik utama di dunia pasca-Perang Dingin.. Menyiasati hal itu, masyarakat perlu dibekali dengan nilai-nilai yang bisa mengikis potensi konflik dan diskriminasi. Pendidikan multikultural dipandang sebagai solusi untuk menjawab persoalan tersebut. Dalam pendidikan multikultural akan diajarkan perilaku menghormati perbedaan dan kemajemukan, menghilangkan kecurigaan, penolakan terhadap kefanatikan individu maupun kelompok (Banks \& Banks, 1989). Dengan pendidikan multikultural sikap saling menghormati akan hadir pada masyarakat sebagai persiapan menuju masyarakat Bantarjati yang majemuk, karena toleransi sangat diperlukan untuk masyarakat yang majemuk (Von Bergen, Von Bergen, Stubblefield, \& Bandow, 2012).

Berdasarkan temuan di lapangan, tim memandang perlu adanya pembinaan kepada masyarakat tentang penguatan budaya toleransi melalui pembinaan nilai-nilai multikultural. Untuk mewujudkan kegiatan itu tim bekerjasama dengan Yayasan Nurussyahid. Yayasan Nurussyahid concern pada bidang pendidikan, seperti Majelis Taklim, Taman Kanak-kanak, Madrasah Diniyah, Taman Pendidikan Al-Qur'an dan Madrasah Aliyah. Kegiatan pembinaan utamanya akan dilakukan kepada para remaja, alasannya karena berdasarkan karakteristik psikologi perkembangan pada usia remaja memiliki ciri sedang mencari jati diri dan termasuk usia yang labil. Sehingga kondisi tersebut memerlukan pembinaan dan pemupukan jati diri, sebagai wahana untuk menumbuhkan nilai, persepsi, dan sikap yang positif serta produktif (Santrock, 2008). 


\section{METODE PELAKSANAAN}

Kegiatan pembinaan ini diharapkan agar masyarakat memiliki pemahaman tentang nilai nilai multikultural (multicultural knowing), meyakini nilai-nilai multikultural (multicultural feeling) dan mampu melaksanakan nilai-nilai multikultural (multicultural action) dalam kehidupan sehari-hari. Dengan pendidikan multikultural sikap saling menghormati akan hadir pada masyarakat. Karena itu metode/model yang akan digunakan adalah model internalisasi nilai. Dengan model ini diharapkan peserta akan memiliki analisa kritis terhadap situasi yang berhubungan dengan suatu konteks sosial (Hakam, 2016). Disamping itu melalui model internalisasi nilai peserta diharapkan mampu menerima nilai-nilai orang lain dengan cara tidak menilai baik dan buruknya, tetapi peserta pun mesti mampu menganalisa data atau informasi sehingga mereka dapat menemukan nilai mereka sendiri dan nilai masyarakat dimana mereka hidup, yang pada akhirnya peserta mampu melakukan penilaian pada suatu nilai secara rasional (Djahiri, 2007). Adapun model internalisasi nilai yang akan digunakan pada pembinaan ini adalah model analisa nilai dan Values Clarification Technique (VCT).

Penggunaan model analisa nilai diharapkan peserta mampu mengumpulkan dan menganalisa data serta mengklasifikasikan setiap informasi yang termasuk pada fakta, opini, asumsi, kriteria, propaganda atau informasi yang salah (Coombs \& Meux, 1971). Sementara model Values Clarification Technique (VCT) adalah model yang dirancang untuk mendukung pilihan nilai-nilai yang intellejen melalui proses choosing, prizing, dan behaving (Rath, Harmin, \& Simon, 1966)). Dengan model tersebut individu bisa menentukan pilihan (choosing) diantara alternatif-alternatif yang tersedia, menentukan tingkat kepentingan (prizing) pada pilihannya, dan bertindak (behave) sesuai dengan pilihannya.

\section{HASIL DAN PEMBAHASAN}

Setelah rute penerbangan domestik dari Bandara Husein Sastranegara dialihkan ke Bandara Internasional Jawa Barat (BIJB) yang melayani 56 penerbangan meliputi 13 rute domestik ke berbagai daerah di Indonesia, beroperasinya tol Cisumdawu dan dijadikannya BIJB sebagai tempat embarkasi haji tahun 2020 serta isu akan pindahnya ibukota Provinsi Jawa Barat ke daerah sekitar bandara mengakibatkan percepatan ekonomi di wilayah tersebut akan berlangsung dengan pesat (Kompas, 2019).

Program pembangunan dan percepatan ekonomi akan mengakibatkan kontak komunikasi dan pertukaranpun semakin meningkat (Azra, 2019). Akibatnya, prasangka dan salah persepsi di antara berbagai kelompok etnik makin berkurang di satu sisi, namun juga kecemburuan sosial di kalangan mereka tumbuh di sisi lain. Apalagi pada awal pembangunan bandara terjadi pro dan kontra karena adanya beberapa wilayah yang ada pada enam desa tergusur akibat adanya bandara BIJB yaitu Desa Kertajati, Bantarjati, Sukakerta, Sukasari, Babakan, Sukamulya. Sehingga pada prosesnya terjadi konflik horizontal dan vertikal.

Dampaknya masyarakat terpecah menjadi dua kelompok yaitu kelompok pendukung dan penolak. Disamping itu perasaan saling curiga antar kelompok masih ada, jenjang pendidikan yang mayoritas belum mengenyam pendidikan tinggi, padahal tingkat pendidikan berdampak pada perilaku toleransi (Sullivan dan Transue, 1999). Hal itu diperparah dengan adanya kesenjangan sosial ekonomi dari pendatang yang 
mayoritas menguasai sektor ekonomi membuat konflik dimungkinkan terjadi. Perbedaan tersebut akan melahirkan benturan antara budaya luar dengan budaya lokal. Fenomena tersebut, kalau tidak diantisipasi akan mengalami disharmoni yang bisa menimbulkan konflik yang berkepanjangan sehingga akan mengganggu keutuhan NKRI. Menghadapi hal itu, warga setempat perlu dibekali dengan nilai-nilai yang menghormati perbedaan dan kemajemukan sehingga bisa menciptakan keharmonisan dalam perbedaan. Pendidikan multikultural dipandang sebagai sebuah solusi untuk menyiasati kondisi tersebut.

Berdasarkan paparan di atas, maka analisis situasi yang telah dilakukan dapat dikatakan bahwa masyarakat perlu diberikan pengetahuan dan pemahaman tentang nilai-nilai multikultural. Oleh karena itu tim berkumpul untuk membuat kurikulum tentang nilai-nilai Multikultural. Hasil pertemuan dengan tim maka melahirkan silabus; Pengertian pendidikan Multikultural dan Nilai-nilai Multikultural, Dasar hukum dan Tujuan pendidikan multikultural, Urgensi Pendidikan Multikultural, Indikator keberhasilan Pendidikan Multikultural, Beberapa tantangan dalam pendidikan multikultural, Nilai-nilai multikultural dan kearifan lokal masyarakat sunda, Nilai-nilai multikultural dalam agama Islam, piagam madinah dan materi lainnya.

Sementara menurut James A. Banks dan Charry A. Banks (1989) kurikulum pendidikan multikultural berisi tentang materi-materi yang dapat menghadirkan lebih dari satu perspektif tentang suatu fenomena kultural. Untuk menghadirkan keragaman perspektif dapat dilakukan dengan empat tahapan, yaitu: (a) tahap kontribusi (contribution level), (b) tahap penambahan (additive level), (c) tahap perubahan (transformative level), dan (d) tahap aksi sosial (social action level) (Indarwati, 2018). Apabila pada tahap kontribusi, kurikulum memfokuskan pada kebudayaan minoritas tertentu, maka pada tahap penambahan, kurikulum memperkenalkan konsep dan tema-tema baru misalnya tema-tema yang terkait dengan multikulturalisme dengan tanpa mengubah struktur kurikulum yang esensial. Selanjutnya, bila pada tahap perubahan, kurikulum memfasilitasi para siswa untuk melihat berbagai isu dan peristiwa dari perspektif budaya minoritas, maka pada tahap aksi sosial, kurikulum mengajak para siswa untuk memecahkan problem sosial yang disebabkan oleh persepsi budaya dalam satu dimensi. Kurikulum berbasis multikultural juga perlu memasukkan materi dan bahan ajar yang berorientasi pada penghargaan kepada orang lain. Dalam hubungan ini, Lynch (1986) merekomendasikan dalam menyampaikan pokok-pokok bahasan multikultural, dengan berorientasi pada dua tujuan, yaitu: (a) penghargaan kepada orang lain (respect for others), dan (b) penghargaan kepada diri sendiri (respect for self). Kedua bentuk penghargaan ini, mencakup tiga ranah pembelajaran (domain of learning). Ketiga ranah pembelajaran tersebut adalah pengetahuan (cognitive), keterampilan (psychomotor), dan sikap (affective).

Setelah menghasilkan silabus pendidikan multikultural. Selanjutnya tim melakukan survei untuk mencari informasi, data dan fakta yang bersifat faktual terkait kondisi di lapangan, tim juga menjalin kontak awal dengan ketua yayasan, kepala sekolah, dan para guru untuk menggali berbagai data dan kebutuhan terkait program pengabdian yang akan dilakukan.Setelah melakukan survei awal, tim juga melakukan pengumpulan berbagai materi melalui jurnal nasional, internasional dan buku-buku terkait nilai-nilai multikultural. Dari hasil pengumpulan materi, tim membuat modul, slide/powerpoint sebagai bahan presentasi, dan juga mengumpulkan berbagai materi video yang dapat diputarkan pada saat pembinaan. Cara tersebut merupakan ikhtiar tim agar materi lebih 
simpel, mudah dicerna, dan suasana kegiatan tidak menjenuhkan sehingga kegiatan dapat berjalan dengan baik.

Dalam melaksanakan program kemitraan masyarakat mengenai nilai-nilai multikultural pada awal-awal diadakan, mitra belum banyak mengetahuinya hal ini terbukti pada kegiatan apersepsi, peneliti memberikan suatu pertanyaan tentang pengertian multikultural namun hanya beberapa orang yang merespon itupun jawabannya melenceng dari substansi dan tidak mengenai sasaran. Dengan kondisi tersebut, peneliti merasa pengabdian yang dilakukan tepat sasaran karena bagi mereka multikultural merupakan sesuatu yang baru. Fenomena itu menjadikan tantangan sekaligus peluang bagi peneliti untuk bekerja keras dan mengemas kegiatan program kemitraan masyarakat agar lebih menarik.

Langkah lain yang digunakan dalam pembinaan ini, adalah diterapkannya model internalisasi nilai yaitu model analisa nilai. Penggunaan model analisa nilai bertujuan membimbing mitra untuk mengggunakan pendekatan yang sistematis dan ilmiah dalam mengumpulkan dan menganalisa data, sehingga mereka dapat menemukan nilai mereka sendiri dan nilai masyarakat yang dianggap paling benar dimana mereka hidup, yang pada akhirnya mitra diharapkan mampu membuat keputusan dan penilaian terhadap suatu nilai yang dapat dipertahankan secara rasional dan agama. Dengan menggunakan model analisa nilai pun diharapkan peserta mampu mengumpulkan dan menganalisa data serta mengklasifikasikan setiap informasi yang termasuk pada fakta, mana yang termasuk pada opini, asumsi, kriteria, propaganda atau informasi yang salah. Dengan kata lain, dalam suatu konflik nilai, peserta latih dapat membedakan apa yang mereka ketahui sebagai fakta (bukti), apa yang mereka duga tetapi tidak dapat membuktikannya (opini atau perkiraan). Melalui berpikir proses evaluatif dan berpikir logis para peserta latih akan mencapai suatu keputusan yang didasarkan serangkaian prinsip nilai, serta mampu melakukan penilaian pada suatu nilai secara rasional.

Selain model analisa nilai juga diimplementasikan model values clarification technique (VCT). VCT adalah model internalisasi nilai yang dirancang untuk mendukung pilihan nilai-nilai melalui proses choosing, prizing, dan behaving. Para peserta latih menentukan apa yang mereka sukai (memilih) diantara alternatif-alternatif yang tersedia, menentukan tingkat kepentingannya (prizing) pada apa yang mereka suaki, dan bertindak (behave) sesuai dengan kepentingannya terhadap apa yang disukai atau inginkan.

Penggunaan model internalisasi nilai diharapkan peserta akan memiliki analisa kritis terhadap situasi yang berhubungan dengan suatu konteks sosial (Hakam, 2016). Disamping itu melalui model internalisasi nilai peserta diharapkan mampu menerima nilai-nilai orang lain dengan cara tidak menilai baik dan buruknya serta peserta pun mampu menganalisa data atau informasi sehingga mereka dapat menemukan nilai mereka sendiri dan nilai masyarakat dimana mereka hidup, yang pada akhirnya peserta mampu melakukan penilaian pada suatu nilai secara rasional.

Pada akhirnya melalui kegiatan pembinaan nilai-nilai multikultural diharapkan membantu peserta didik (masyarakat) mengembangkan kemampuan menilai situasi konflik nilai secara logis dan sistematis sampai pada penentuan keputusan nilai yang sahih, dapat dipertanggungjawabkan dan reliabel. Juga membantu pekerjaan peserta didik secara individual maupun kelompok untuk menganalisa situasi secara ilmiah, sehingga secara berangsur dapat mengembangkan sistem nilai yang diterima secara, adil 
secara moral dan konsisten dengan prinsip-prinsip demokrasi dan ketuhanan. Dengan nilai-nilai multikultural diharapkan akan menghasilkan profil manusia yang siap untuk memasuki era millenium ketiga sebagaimana mana menurut Tilaar (2004) dalam Tabel 1.

Tabel 1. Profil Manusia Indonesia Era Milenium Ketiga

\begin{tabular}{|c|c|c|c|}
\hline No & Pancasila & Nilai yang diperlukan & Sumber Nilai \\
\hline 1 & $\begin{array}{l}\text { Ketuhanan yang } \\
\text { maha Esa }\end{array}$ & $\begin{array}{l}\text { Nilai-nilai Etika } \\
\text { Nilai moral }\end{array}$ & $\begin{array}{l}\text { Agama } \\
\text { Kebudayaan }\end{array}$ \\
\hline 2 & $\begin{array}{l}\text { Perikemanusiaan } \\
\text { yang adil dan } \\
\text { beradab }\end{array}$ & $\begin{array}{l}\text { HAM } \\
\text { Toleransi } \\
\text { Kerukunan hidup } \\
\text { antarwarga/antaragama } \\
\text { Kerjasama global untuk } \\
\text { kemakmuran dan perdamaian }\end{array}$ & $\begin{array}{l}\text { Kesadaran hukum } \\
\text { Kerjasama internasional }\end{array}$ \\
\hline 3 & $\begin{array}{l}\text { Persatuan } \\
\text { Indonesia }\end{array}$ & $\begin{array}{l}\text { Saling menghargai perbedaan } \\
\text { Kemauan untuk bersatu } \\
\text { Menghargai simbol-simbol } \\
\text { negara persatuan } \\
\text { Rasa bangga sebagai orang } \\
\text { Indonesia } \\
\end{array}$ & $\begin{array}{l}\text { Bahasa Indonesia } \\
\text { Sistem pendidikan dan } \\
\text { persekolahan } \\
\text { Interaksi } \\
\text { antarwarga/antarsuku } \\
\text { Pendidikan multikultural } \\
\end{array}$ \\
\hline 4 & Kerakyatan & $\begin{array}{l}\text { Nilai-nilai demokrasi } \\
\text { Populis (memihak kepada } \\
\text { kepentingan rakyat) } \\
\text { Teknologi yang memajukan } \\
\text { kemakmuran rakyat }\end{array}$ & $\begin{array}{l}\text { Berfungsinya lembaga- } \\
\text { lembaga demokrasi } \\
\text { Iptek }\end{array}$ \\
\hline 5 & $\begin{array}{l}\text { Keadilan sosial } \\
\text { bagi seluruh } \\
\text { Rakyat Indonesia }\end{array}$ & $\begin{array}{l}\text { Rasa solidaritas sosial sebagai } \\
\text { suatu abng }\end{array}$ & $\begin{array}{l}\text { Lembaga-lembaga sosial } \\
\text { tradisional yang masih } \\
\text { fungsional di daerah }\end{array}$ \\
\hline
\end{tabular}

Dengan nilai multikultural individu akan mengakui kebudayaan beragam sekaligus pula kesediaan dan ketulusan untuk menghargai kebudayaan yang berbeda tanpa harus mengorbankan loyalitas atas identitas kulturalnya sendiri. Multikultural juga melahirkan prinsip jangan ada yang menyakiti (Mill, 1977) semua kelompok sosial, etnis memiliki status dan hak yang sama (Fraser 2002) serta tahan dengan sesuatu yang tidak disukai (Vogt, 1997).

Untuk mencapai hal itu bukanlah sesuatu yang mustahil, karena kearifan lokal budaya Sunda mengajarkan prinsip tersebut, dalam budaya Sunda ada istilah someah $\mathrm{ka}$ semah (perilaku ramah terhadap tamu atau sesuatu yang datang kepadanya), silih asah (saling menajamkan ilmu pengetahuan), silih asih (saling mengasihi, saling menyayangi), dan silih asuh (saling membimbing) (Samani \& Hariyanto, 2012).

\section{SIMPULAN}

Pendidikan multikultural menemukan relevansinya untuk masyarakat Kecamatan Kertajati khususnya Desa Bantarjati yang wilayahnya banyak terkena dampak pembangunan Bandara Internasional Jawa Barat (BIJB). Keberadaan Bandara BIJB akan memiliki daya tarik yang besar dalam menarik wisatawan asing maupun lokal untuk 
datang berkunjung. Imbasnya adalah peningkatan perekonomian masyarakat. Namun yang perlu disadari bahwa dengan hadirnya para wisatawan akan membawa budaya, suku, agama, bahasa dan gaya hidup yang berbeda dengan masyarakat Kecamatan Kertajati yang kental nilai kekeluargaan, gotong royong, dan mencintai kearifan lokal peninggalan leluhurnya, sehingga potensi konflik sangat besar kalau tidak segera diatasi solusinya.

Program Pembinaan kepada masyarakat melalui penyuluhan nilai-nilai multikultural diyakini dapat menjadi solusi nyata bagi konflik dan disharmonisasi yang terjadi di masyarakat, khususnya yang kerap terjadi di masyarakat Indonesia yang secara realitas plural (Ansori, Budiman, \& Nahdi, 2019). Dengan kata lain, pendidikan multikultural dapat menjadi sarana alternatif pemecahan konflik sosial budaya. Selain sebagai sarana alternatif pemecahan konflik, pendidikan multikultural juga signifikan dalam membina masyarakat agar tidak tercerabut dari akar budaya yang ia miliki sebelumnya, tatkala ia berhadapan dengan realitas sosial budaya di era globalisasi. Melalui kegiatan PKM ini diharapkan masyarakat Bantarjati Kecamatan Kertajati akan memiliki sikap yang bijak dalam menghadapi perbedaan dan menghargai keberagaman budaya diharapkan menjadi modal utama bagi warga masyarakat sehingga mereka menjadi pribadi yang berwawasan lebih luas serta mampu bersosialisasi di tengah keragaman masyarakat.

\section{REFERENSI}

Alwasilah, A. C. (2012). Pokoknya rekayasa literasi. Bandung: Kiblat.

Ansori, Y. Z., Budiman, I. A., \& Nahdi, D. S. (2019). Islam dan pendidıkan multıkultural. Jurnal Cakrawala Pendas, 5(2), 110-115.

Azra, A. (2019). Cultural Pluralism In Indonesia: Continuous Reinventing of Indonesian Islam in Local, National and Global Contexts. Asia Pacific Journal on Religion and Society, 2(2), 56-60.

Banks, J. A., \& Banks, C. A. (1989). Multicultural education. Issues and perspectives, 1. London: Allynand Bacon Press.

Coombs, J. R., \& Meux, M. (1971). Teaching strategies for value analysis. Washington, DC: National Council for the Social Studies.

Djahiri, K. (2007). Kapita selekta pembelajaran. Bandung: Lab PMPKN FPIPS UPI Bandung.

Fraser, N. (2002), Recognition without Ethics?. In Lash, Scott et al. (eds.), Recognition and difference. London: Sage Publications.

Hakam, K. A. (2016). Metode internalisasi nilai-nilai. Bandung: Maulana Media Grafika.

Huntington, S. (1992). The Clash of Civilizations. Washington, DC: American Enterprise Institute. 
Indarwati, K. (2018). Penerapan pendidikan multikultural di pondok pesantren AlMuayyad Surakarta. Comm-Edu (Community Education Journal), 1(3), 121-132.

Lynch, J. (1986). Multicultural education: Principles and practice. London: Routledge \& Kegan Paul.

Mill, J. S. (1977). On liberty collected works of John Stuart Mill. Toronto: University of Toronto Press.

Rath, L., Harmin, M., \& Simon, S. (1966). Values and teaching: Working with values in the classroom. Columbus, Ohio: Charles Merrill.

Samani, M., \& Hariyanto, M. S. (2012). Konsep dan model pendidikan karakter. Bandung: Remaja Rosdakarya.

Santrock, J. W. (2012). Life span development. Jakarta: Erlangga.

Sullivan, J. L., \& Transue, J. E. (1999). The psychological underpinnings of democracy: A selective review of research on political tolerance, interpersonal trust, and social capital. Annual Review of Psychology, 50(1), 625-650.

Tilaar, H. A. R. (2004). Multikulturalisme: Tantangan global masa depan dalam transformasi pendidikan nasional. Jakarta: Gramedia Widiasarana Indonesia.

Vogt, W. P. (1997). Tolerance and education: Learning to live with diversity and difference. Thousand Oaks, CA: Sage Publications.

Von Bergen, C. W., Von Bergen, B. A., Stubblefield, C., \& Bandow, D. (2012). Authentic tolerance: between forbearance and acceptance. Journal of Cultural Diversity, 19(4), $111-117$ 